\title{
A new model of inexpensive portable homemade PERC Mentor (IPHOM) and its validation
}

\author{
Abhishek Shukla ${ }^{1 *} \mathbb{D}$, Gurwinder Sethi ${ }^{2}$, Ananya Dutta ${ }^{3}$, Puneet Aggarwal ${ }^{4}$ and Ayon Gupta ${ }^{5}$
}

\begin{abstract}
Background: Percutaneous nephrolithotomy (PCNL) is a complex surgery and has a flat learning curve. Due to this and the ethical issues, trainees do not get enough hands on exposure. Virtual simulator is very expensive and bulky. Animal model requires legal clearance. This inexpensive portable homemade PERC Mentor (IPHOM) teaches all the major aspects of PCNL surgery. This article has shown the way to make this model and its validation study.

Methods: IPHOM can be made at home with carton box, ball bearings, LED torch and some hospital wastes. After a short demonstration of IPHOM, 14 residents and 4 urologists were given 8 tasks to perform on it followed by 15 -min supervised practice exercise on day 0 and day 1. Their performance was reassessed on day 2 and 3. Response to 17 feedback points was recorded on a seven-point Likert scale.

Results: There was significant difference between the performance of expert and novice on day 0 . Expert completed all the tasks in less time and no. of attempts. The time for tract dilatation and duration of radiation exposure were significantly less in the expert group. The performance of both expert and novice improved on day 2 and 3 , but the improvement was significantly more in novice. Response to the feedback points showed no difference between expert and novice $(p>.05)$.
\end{abstract}

Conclusions: We have found that training on IPHOM has improved the concept and skills of PCNL in residents. The simplicity and low cost of the model make it constructible at home.

Keywords: C-arm, PCNL, PERC Mentor, Training, Simulator

\section{Background}

Urolithiasis is one of the most common presentations in urology OPD. One of the methods of treating renal stones is PCNL. It is a complex surgery with flat learning curve [1]. There are ethical issues in giving this complex surgery to a trainee to perform on a patient. The surgery involves not only the surgical aspects of handling the tissue, but also the radiological aspect of visualizing the kidney in $\mathrm{C}$-arm in an imaginary 3D structure from the 2D image. Apart from tissue injury and contrast extravasation by a

\footnotetext{
*Correspondence: shuki_79@yahoo.co.in

${ }^{1}$ Faculty Department of Urology, Command Hospital, Pune, India Full list of author information is available at the end of the article
}

wrong puncture, multiple firing of C-arm by an untrained trainee leads to increased radiation exposure to OT staff and the patient [2]. The tense OT atmosphere and pressure of completing the case in time do not allow the resident to learn this complex surgery with a free mind. Animal models require logistics of the animal laboratory, processing of animal, availability of OT and $\mathrm{C}$-arm and legal clearance which is difficult in the present scenario $[3,4]$. There is also a risk of infection from animal tissues. Virtual PERC simulators are very costly [5]. Though these mentors also teach about lower tract endoscopic procedures, our residents are already doing these across various centers. Our new innovation IPHOM is an extremely low-cost, homemade and lightweight mentor with an 
internal $\mathrm{C}$-arm, which teaches all the major aspects of PCNL till the dilatation of tract

\section{Methods}

\subsection{Construction of IPHOM}

PERC Mentor Box: Carton box of dimensions of $45 \times 45 \times 35 \mathrm{~cm}(\mathrm{LxHxW})$.

Rib and vertebrae are made of cardboard placed in the box (Fig. 1), laminated white paper to simulate skin surface which captures the calyceal shadow (Fig. 2).

Kidney replica and $\mathrm{C}$-arm: Calyces are made by used needle cap or used laboratory pipettes or straw. Straw is glued to use PCN sheath. Needle cap and pipettes are glued to the dropper which is easily available from used pediatric syrup which is then mounted onto the chest tube trocar. The advantage of using the dropper is that it is cheap and easily available. Due to hollow lumen, it can be easily mounted on the trocar and is changeable, so on the same trocar, a dropper with variable calyceal anatomy can be mounted and practiced (Fig. 3a). C-arm is made of cardboard sheets that are cut and joined to make a U-shape (horizontal) and L-shape (vertical) arm (Fig. 3c). Two ball bearings are attached at the end of the horizontal arm, move the $\mathrm{C}$-arm in the craniocaudal direction, and the one attached at the center moves it in the mediolateral direction. LED torch bulb connected with push-button switch simulates $\mathrm{C}$-arm foot pedal (Fig. 3b and c).

\subsection{Validation of the model}

The protocol was approved by the institutional ethics committee (No-114/2020). Nine urology residents and five general surgery residents were grouped as novice, and four urologists as experts participated in this study. Urology residents had varying degrees of experience of PCNL, from observing (three Ist year trainees), assisting (three 2nd year trainees) to assisting and performing at least 2 surgery under supervision (three final-year residents). General surgery residents had never seen PCNL before. Experts had performed at least 150 PCNL surgeries. After a short introduction of IPHOM and PCNL, they were asked to perform 8 tasks from identification of posterior calyx to dilatation of tract on day 0 (Table 1 ). Their initial performances along with the duration of exposure to LED light (equivalent to the radiation exposure in a real scenario) while placing the guidewire and tract dilatation were recorded separately. After the supervised practice for $30 \mathrm{~min}$ on day 0 and day 1 , their performances were reassessed on days 2 and 3 . A seven-point

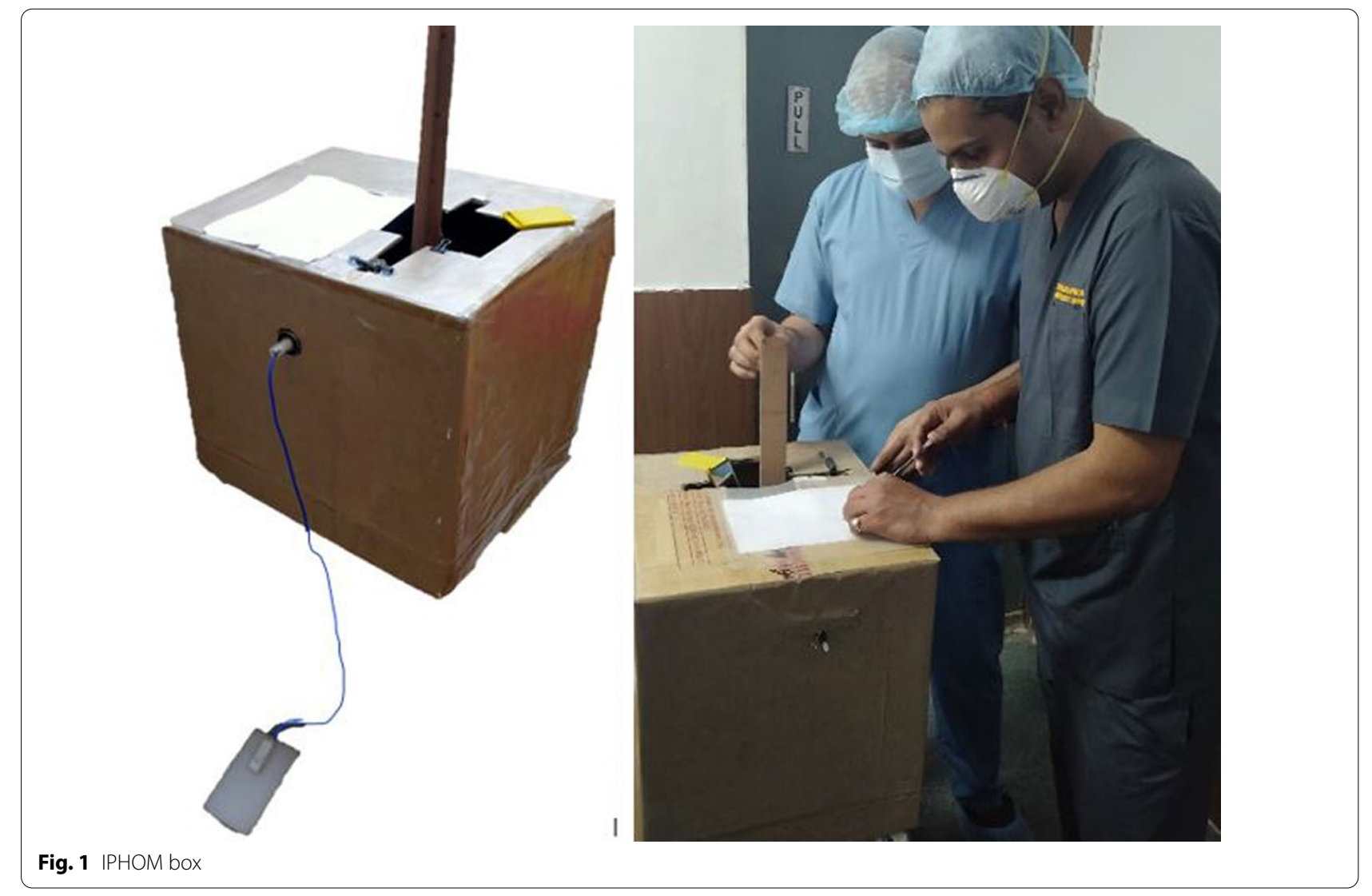






Fig. 2 a Replica of Calyx and Spine and $\mathbf{b}$ Calyx image captured on laminated white paper
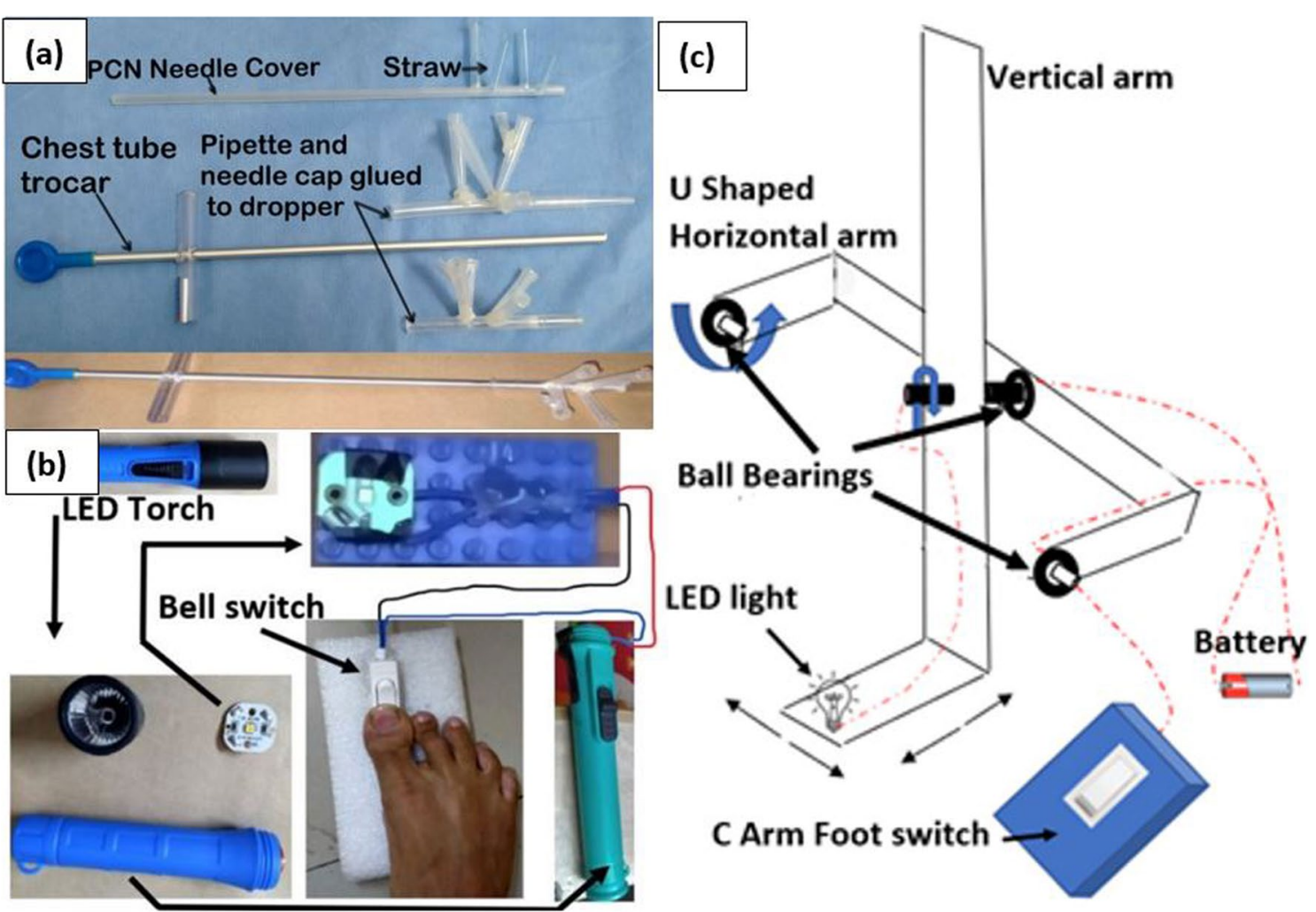

Fig. 3 a Calyceal replica b Making C-arm foot switch and light arm assembly source using LED torch c C-arm assembly 
Table 1 Comparison of mean number of attempts and time taken for various tasks performed by expert and novice on day 0, 2 and 3

\begin{tabular}{|c|c|c|c|c|c|c|c|}
\hline & \multirow[t]{2}{*}{ Task given } & & \multicolumn{2}{|c|}{ Expert $(n=4)$} & \multicolumn{2}{|c|}{ Novice $(n=14)$} & \multirow[t]{2}{*}{$P$ value } \\
\hline & & & Mean & Std dev & Mean & Std dev & \\
\hline \multirow[t]{18}{*}{ No of attempts } & \multirow[t]{3}{*}{ Identify posterior calyx } & Day 0 & 1 & 0 & 2.21 & 0.57 & 0.000 \\
\hline & & Day 2 & 1 & 0 & 1.21 & 0.42 & 0.339 \\
\hline & & Day3 & 1 & 0 & 1 & 0 & \\
\hline & \multirow{3}{*}{$\begin{array}{l}\text { Identify needle position with respect } \\
\text { to calyx }\end{array}$} & Day 0 & 1 & 0 & 2.64 & 0.74 & 0.000 \\
\hline & & Day 2 & 1 & 0 & 1.28 & 0.46 & 0.250 \\
\hline & & Day3 & 1 & 0 & 1.07 & 0.26 & 0.608 \\
\hline & \multirow[t]{3}{*}{ Puncture the calyx } & Day 0 & 1.25 & 0.5 & 3.35 & 0.49 & 0 \\
\hline & & Day 2 & 1 & 0 & 1.64 & 0.49 & 0.022 \\
\hline & & Day3 & 1 & 0 & 1.5 & 0.51 & 0.077 \\
\hline & \multirow[t]{3}{*}{ Place the guidewire } & Day 0 & 1.25 & 0.5 & 3 & 0.87 & 0.001 \\
\hline & & Day 2 & 1 & 0 & 1.71 & 0.46 & 0.008 \\
\hline & & Day3 & 1 & 0 & 1.57 & 0.51 & 0.044 \\
\hline & \multirow[t]{3}{*}{ Perform bulls Eye } & Day 0 & 1.5 & 0.57 & 2.85 & 0.36 & 0 \\
\hline & & Day 2 & 1 & 0 & 1.64 & 0.49 & 0.022 \\
\hline & & Day3 & 1.25 & 0.5 & 1.35 & 0.49 & 0.709 \\
\hline & \multirow[t]{3}{*}{ Perform gradual descent } & Day 0 & 1.75 & 0.5 & 3 & 0 & 0 \\
\hline & & Day 2 & 1.25 & 0.5 & 2 & 0.55 & 0.027 \\
\hline & & Day3 & 1 & 0 & 1.35 & 0.63 & 0.286 \\
\hline \multirow[t]{9}{*}{ Time taken(sec) } & \multirow[t]{3}{*}{ Triangulation technique } & Day 0 & 57.5 & 5 & 136 & 35.33 & 0.001 \\
\hline & & Day 2 & 50 & 4.08 & 89.64 & 39.39 & 0.066 \\
\hline & & Day 3 & 45.25 & 4.27 & 56.78 & 19.57 & 0.268 \\
\hline & \multirow[t]{3}{*}{ Tract Dilatation } & Day 0 & 117.5 & 34.03 & 217.72 & 66.98 & 0.007 \\
\hline & & Day 2 & 85 & 5.7 & 140.71 & 66.99 & 0.061 \\
\hline & & Day 3 & 67.5 & 9.57 & 98.64 & 31.83 & 0.076 \\
\hline & \multirow[t]{3}{*}{ Duration of Radiation exposure } & Day 0 & 87.5 & 22.17 & 200 & 68.15 & 0.007 \\
\hline & & Day 2 & 68.75 & 2.5 & 127.14 & 88.78 & 0.216 \\
\hline & & Day 3 & 53.75 & 11.08 & 66.07 & 20.67 & 0.275 \\
\hline
\end{tabular}

Likert response to 17 feedback questions was obtained from each participant.

\subsection{Statistical analysis}

Paired $\mathrm{T}$ test was used to assess the performance of novice and experts on different days. The Student's T test was used to compare both the groups on different days and to analyze the difference in response of face and content questionnaire [6]. Pearson's correlation coefficient was used to determine associations between the experience of participants with the number of attempts and time taken.

\section{Results}

Novice took more time and attempts to perform all 8 tasks than experts. Independent $\mathrm{T}$ test showed a significant difference in their performance. The difference was more on day $0(p<0.05)$ in comparison with days 2 and $3(p>0.05)$, indicating that the novice had learned the skills and performed close to the experts. The mean of attempts in identifying the posterior calyx and needle position on day 0 was $E=1 ; N=2.2$ and $E=1 ; N=2.64$, which improved to $E=1 ; N=1$ and $E=1 ; N=1.07$ $(p<0.05)$ on day 3. Similarly for other tasks, Novice performed close to experts on days 2 and 3 (Table 1). Within the group, paired $\mathrm{T}$ test showed significant improvement in their performance on days 2 and 3 in comparison with day $0(p<0.05)$; however, this was more marked in novice. Guidewire displacement during tract dilatation by novice was 3.5 times on day 0 and 0.9 times on day $3(p<0.05)$. Similarly, mean time taken for triangulation technique, tract dilatation, and duration of radiation exposure reduced significantly from day 0 to day $3(p<0.05)$ (Fig. 4). Within the group, there was no significant difference in performance between day 2 and day 3. Pearson correlation coefficient was calculated between the level of experience of operators and all parameters on day 0 . A moderate negative linear relationship ranging from -0.5 in no. of attempts taken to place guidewire to -0.7 in attempts taken to cannulate bull's eye was noted. However, after training 


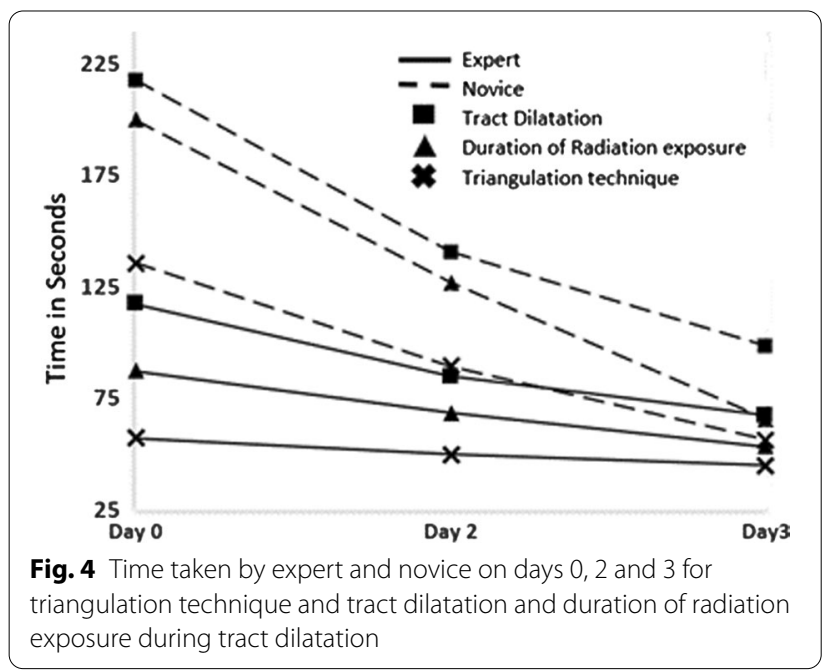

when correlation coefficient was calculated between the level of experience and attempts taken to cannulate bull's eye, no correlation was noted $(r=0.05)$. There was no significant difference in the opinion of novices and experts in response to the 17 feedback questions (Fig. 5) with the mean of response in seven-point Likert scale for novice being 6.1 (range 4-7) and for expert being 5.9 (range $3.5-7)(p>0.05)$.

\section{Discussion}

Halstedian model of teaching one at a time is an ideal way of teaching, but it is not possible in the current scenario, especially for surgeries like PCNL [7]. It is a complex procedure that involves puncturing the desired calyx by analyzing the calyceal images and their movements with respect to $\mathrm{C}$-arm movement [8]. This is the most important step; after this, the stone fragmentation is done under direct vision which is not difficult and can be supervised easily. A wrong puncture can lead to bleeding or contrast extravasation. With practice, one can learn to puncture the desired calyx accurately. With the increasing number of residents, adequate handson training is not possible. When residents do the case, there are more complications and radiation exposure. ${ }^{2}$ Moreover, there are increasing litigation issues from the patient side and pressure from OT to finish the case in time [9]. Alternate training models like virtual simulators (PERC Mentor, Simbionix) are extremely costly [10]. They are software based, so problems related to image overlapping and hand to image delay are frequently encountered $[11,12]$. It does not have C-shaped real arms but has the software-based unrealistic C-arm seen on the monitor where manual movement is lacking, whereas residents have to physically move the $\mathrm{C}$-arm in different planes in a real scenario. Also, the guidewire is inserted not through the puncture needle but

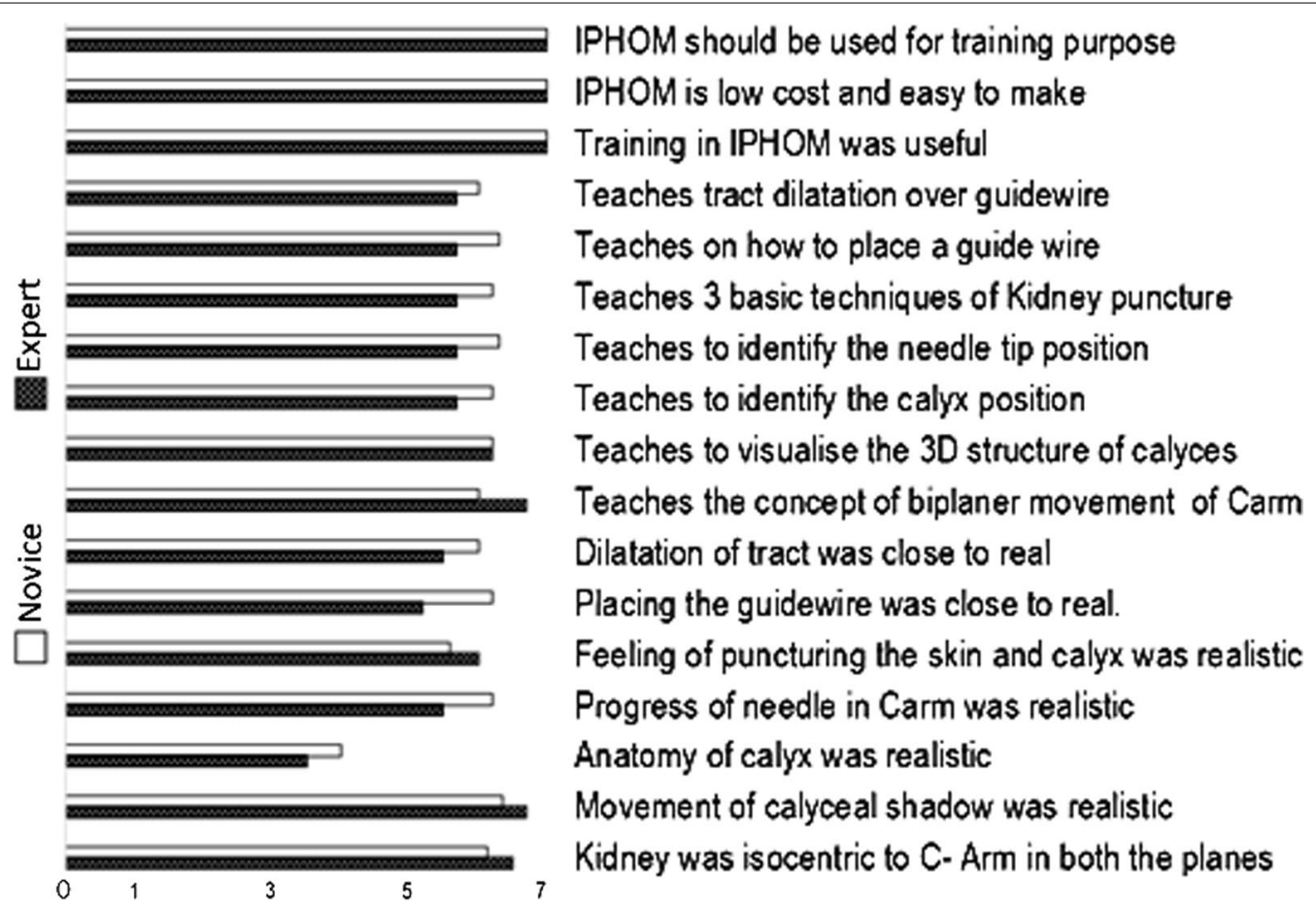

Fig. 5 Response in 7 point Likert scale to 17 feedback questionnaire 
from a different slot which is unrealistic. Animal models have issues of license and infrastructure $[4,13]$. It is not available at smaller centers. It requires the processing of tissues; hence, there is a risk of contamination of OT instruments. OT and $\mathrm{C}$-arm remain occupied during animal-based training, so the risk of radiation exposure and damage to the $\mathrm{C}$-arm machine is still there. Karagozlu Akgulet et al. described a nonbiological model for PCNL training using rubber foam and play dough [14]. But it requires $\mathrm{C}$-arm; hence, risk of radiation exposure is there. Secondly, there is no provision of placing guidewire and tract dilatation. Zang et al. described another non-biological model constructed of silicone [15]. Apart from cost and risk of radiation, the main disadvantage of this model is that residents have one design to practice, so she/he tends to memorize the anatomy. Turney et al. made the training model using 3D printing technology using images extracted from computer tomography pictures with a special software [5]. Apart from cost and need for technology, the long preparation period of 2-3 days and requirement of fluoroscopy are the drawbacks of this tool. If the contrast leaks out, the model is required to be changed. Similarly, other models based on 3D printing technology are available, but these have similar drawbacks. Sinha M and Krishnamoorthy V described a low-fidelity training model [16]. They used bottle guard as kidney replica and $\mathrm{C}$-arm. The main drawback was less maneuverability of the needle inside the bottle guard. Apart from this, there was no provision for guidewire placement and tract dilatation. The model was unrealistic in appearance and was not radiation-free. Radiation-free $\mathrm{C}$-arm trainer (SimPORTAL, Minneapolis, USA) consists of two video cameras mounted on a mini C-arm [17]. The images produced are processed by computer software to create an X-ray image of an anatomically accurate silicon flank model for needle insertion. The drawbacks of this model were the following: it required a computer with the software and could not teach guidewire placement and tract dilatation. Moreover, a couple of sessions on these high-cost models or real patients do not improve the PCNL skills significantly as the learning curve of this complex surgery is up to 60 cases, even more than RARP [18]. It requires skill to imagine the $2 \mathrm{D}$ image of $\mathrm{C}$-arm into a virtual 3D image and hand-eye coordination which comes with repeated practice [8]. To solve these problems, this PERC Mentor has been built using simple things which are easily available at home and hospital waste products. Unlike a virtual simulator, it is extremely cheap, homemade, and portable. It has an internal C-arm that moves in an isocentric manner in mediolateral and craniocaudal planes. Since the image is captured onto the laminated white paper, which is also the area of skin puncture, it does not require the bulky $\mathrm{C}$-arm monitor or any electrical connection, which makes it compact and portable. There is no risk of radiation exposure, limitation of OT time, or risk of injury to the patient. So, the residents can practice in a stress-free environment. In IPHOM, guidewire is placed through the PCN puncture needle like it is done in the patient. This feature is lacking in virtual simulator which has a separate slot for putting the guidewire which is unrealistic [11, 12]. After a wrong puncture, one would like to know the position of the needle with respect to the calyx to have an idea of the direction of needle tract so that he can correlate it with the movement of its image in the C-arm This is not possible in real patient and other training models as one cannot directly look inside. Our model has a flip-open mirror system that can be used after the wrong puncture, and then it can be closed back. On inserting the PCN needle, two puncture sensations are felt, first at the skin and second at renal capsule or calyx. The PERC Mentors available give a haptic feeling of only skin puncture [11]. IPHOM gives the feeling of puncture at the skin (laminated paper) and kidney (calyx tip covered by thin transparent tape). The only consumable required in this model is the laminated paper; after multiple punctures, it has to be changed. This can be made at home with transparent tape and white paper. We have made different calyceal replicas from simple nonoverlapping distantly placed calyces for beginners to difficult closely placed overlapping and crossing calyces for more experience and to avoid memorizing the anatomy of the calyx.

In the validation study, we have found that experts were significantly better than novice in their initial performance $(p<0.05)$. Although the experts improved in subsequent days, novice showed significantly better improvement, and the difference in the performance between expert and novice reduced on day 2 and day $3(p>0.05)$. This supports the construct nature of the mentor, as various techniques, which are used in real patients and virtual simulators, can also be performed on this mentor. Paired $\mathrm{T}$ test independently showed significant improvement in the performance of novice from day 0 to day 2 which was reproducible on day 3 . In the OT, triangulation technique is generally not well learned by residents as it requires frequent biplanar movements of heavy $\mathrm{C}$-arm from mediolateral to oblique [8]. This is cumbersome, so surgeon resorts to simpler technique like bulls' eye technique which has a shorter learning curve [19]. This mentor has easy $\mathrm{C}$-arm movements due to its light weight; hence, the residents can attempt multiple punctures and learn the concept of triangulation technique. Pearson correlation coefficient showed a moderate negative linear relationship $(-0.5$ to -0.7$)$. The more experienced operators took less attempt and time to finish the task. After 
Table 2 Comparison of various PCNL training models with IPHOM

\begin{tabular}{|c|c|c|c|}
\hline & Virtual uromentor & Other low cost mentors [20] & IPHOM \\
\hline Cost & Extremely costly (> Rs 45,00,000.00) & RS $1,50,000.00$ & Rs 250.00 \\
\hline Manufacturing & Factory (Imported) & Factory & Homemade \\
\hline Size and portability & Bulky and heavy & Bulky and heavy & Lightweight and portable \\
\hline $\begin{array}{l}\text { External electric connection } \\
\text { required }\end{array}$ & Yes & Yes & No \\
\hline $\begin{array}{l}\text { Haptic feeling of skin and calyceal } \\
\text { puncture }\end{array}$ & Only skin puncture is felt & Only skin puncture is felt & $\begin{array}{l}\text { Yes [skin(laminated paper) and calyx } \\
\text { (transparent tape covering the ends } \\
\text { of pipette)] }\end{array}$ \\
\hline Guide wire placement & $\begin{array}{l}\text { Unrealistic way, small guidewire, } \\
\text { placed from side slot and not } \\
\text { through PCN needle }\end{array}$ & Not provided & $\begin{array}{l}\text { Guide wire placement through PCN } \\
\text { needle }\end{array}$ \\
\hline C-arm & $\begin{array}{l}\text { Virtual C-arm (Software based) No } \\
\text { realistic feeling of manual move- } \\
\text { ment }\end{array}$ & $\begin{array}{l}\text { C-arm (External). Makes it heavy } \\
\text { and bulky }\end{array}$ & $\begin{array}{l}\text { C-arm (Internal) Movable in isocentric } \\
\text { manner. Makes it light and portable }\end{array}$ \\
\hline Dilatation over guidewire & No & No & Yes \\
\hline $\begin{array}{l}\text { Real time checking the position of } \\
\text { needle with respect to calyx }\end{array}$ & No & No & $\begin{array}{l}\text { Yes (Flip open mirror to check final } \\
\text { position after the attempt) }\end{array}$ \\
\hline $\begin{array}{l}\text { Availability of variable calyceal } \\
\text { anatomy for training }\end{array}$ & Yes & No & Yes \\
\hline
\end{tabular}

training on IPHOM, this correlation was not seen. When the correlation coefficient was calculated for the bull's eye technique on day 3 , no correlation was noted. $(r=0.05)$ This suggests that training had obviated the correlation between the level of experience and cannulation attempts.

In the feedback to the 17 questions, there was no significant difference found in the opinion of expert and novice. All agreed that the mentor was easy to make at home, able to teach them the essential concept of $\mathrm{C}$-arm movement, calyceal positioning, puncturing techniques and it could be utilized for training purpose. We have compared the common training models with IPHOM in Table 2.

There are limitations of this mentor in comparison to the virtual simulator. There are no respiratory movements. In real patients, contrast is required to visualize calx [8]. In this model, calyces are already visible, as they form shadow on the laminated paper. After puncturing the calyx, urine efflux through the puncture needle is not seen, but this feature is also lacking in high-fidelity simulators $[10,12]$. The guidewire cannot be placed in the ureter or in the pelvis as there is no ureter, so there are high chances of its displacement during tract dilatation. However, this is rather good for training, as the resident will get used to the careful handling of the guidewire. Virtual simulators also teach about ureteroscopy, cystoscopy, and optical internal urethrotomy which this mentor does not [12]. But most of the residents are already doing the lower tract endourological procedures and ureteroscopy at various centers. So, wasting money on software for these procedures is not justified.

\section{Conclusions}

Teaching PCNL to residents on real patients is not preferred due to safety and ethical issues. Alternatives like virtual simulators are extremely costly. This article shows the method to construct IPHOM, a low-cost PERC Mentor, at home. The validation study has shown that the trainees have learned the concept of image movement in $\mathrm{C}$-arm, basic renal puncture techniques, and tract dilatation over the guidewire on this mentor. In face and content validation, all participants agree that this training model is easy to make, low cost and teaches basic PCNL puncture techniques in a tension-free and radiation-free environment.

\footnotetext{
Abbreviations

PCNL: Percutaneous nephrolithotomy; IPHOM: Inexpensive portable homemade PERC Mentor; 2D or 3D: Two dimensions or three dimensions; OPD: Outpatient department; OT: Operation theatre; LXHXW: Length $\times$ height $\times$ width; RARP: Robotic assisted radical prostatectomy.
}

\section{Authors' contributions}

AS has contributed toward concepts and design of the study, data acquisition and analysis, interpretation of data, drafting the manuscript and manuscript review for final approval. GS has significantly contributed in, data acquisition and manuscript editing. AD has contributed in design of the study, data acquisition, interpretation of data and manuscript preparation. PA has contributed in literature search data acquisition, data analysis and manuscript preparation. AG has contributed in data analysis, interpretation of data and manuscript editing. All authors read and approved the final manuscript.

\section{Funding}

None. 


\section{Availability of data and materials}

The datasets used and/or analyzed during the current study are available from the corresponding author on reasonable request.

\section{Declarations}

\section{Ethics approval and consent to participate}

There were no patients or live subjects on whom intervention was done. So consent was not obtained from any patients as there were none. It was an exercise on the innovative training model (inanimate) for which the residents and the senior doctors gave the written consent and the protocol was cleared by the Institutional Ethics Committee, Army Hospital R\&R, Delhi, Cantt: IEC Reg No- 114/2020

\section{Consent for publication}

Not applicable.

\section{Competing interests}

The authors declare that they have no competing interest.

\section{Author details}

${ }^{1}$ Faculty Department of Urology, Command Hospital, Pune, India. ${ }^{2}$ of Department of Urology, Army Hospital R\&R, New Delhi, India. ${ }^{3}$ Department of Urology, Command Hospital, Kolkata, India. ${ }^{4}$ Faculty Department of Urology, Army Hospital R\&R, New Delhi, India. ${ }^{5}$ Centre for Community Medicine AllMS, New Delhi, India.

Received: 7 June 2021 Accepted: 13 September 2021

Published online: 11 October 2021

\section{References}

1. Ng CF (2014) Training in percutaneous nephrolithotomy: The learning curve and options. Arab J Urol 12(1):54-57. https://doi.org/10.1016/j.aju. 2013.08.002

2. DeSimone AK, Post A, Duszak R Jr, Duong PT (2018) Radiology Trainee vs Faculty Radiologist Fluoroscopy Time for Imaging-Guided Procedures: a Retrospective Study of 17,966 Reports Over a 5.5-Year Period. Curr Probl Diagn Radiol 47(4):233-237. https://doi.org/10.1067/j.cpradiol.2017.07. 003

3. Vijayakumar M, Balaji S, Singh A, Ganpule A, Sabnis R, Desai M (2019) A novel biological model for training in percutaneous renal access. Arab J Urol 17(4):292-297. https://doi.org/10.1080/2090598X.2019.1642600

4. Bergmeister KD, Aman M, Kramer A et al (2020) Simulating surgical skills in animals: systematic review, costs \& acceptance analyses. Front Vet Sci 7:570852. https://doi.org/10.3389/fvets.2020.570852

5. Turney BW (2014) A new model with an anatomically accurate human renal collecting system for training in fluoroscopy-guided percutaneous nephrolithotomy access. J Endourol 28(3):360-363. https://doi.org/10. 1089/end.2013.0616

6. Schout BM, Hendrikx AJ, Scheele F, Bemelmans BL, Scherpbier AJ (2010) Validation and implementation of surgical simulators: a critical review of present, past, and future. Surg Endosc 24(3):536-546. https://doi.org/10. 1007/s00464-009-0634-9
7. Kotsis SV, Chung KC (2013) Application of the "see one, do one, teach one" concept in surgical training. Plast Reconstr Surg 131(5):1194-1201. https://doi.org/10.1097/PRS.0b013e318287a0b3

8. Sharma GR, Maheshwari PN, Sharma AG, Maheshwari RP, Heda RS, Maheshwari SP (2015) Fluoroscopy guided percutaneous renal access in prone position. World J Clin Cases 3(3):245-264. https://doi.org/10.12998/ wjcc.v3.i3.245

9. Bajpai MK. Patients are now suing doctors at an alarming rate Available from: https://health.economictimes.indiatimes.com/videos/patients-arenow-suing-doctors-at-an-alarming-rate-mahendrakumar-bajpai/51466 905

10. White MA, Dehaan AP, Stephens DD, Maes AA, Maatman TJ (2010) Validation of a high fidelity adult ureteroscopy and renoscopy simulator. J Urol 183(2):673-674. https://doi.org/10.1016/j.juro.2009.10.013

11. Gundeti MS. Surgical Techniques in Pediatric and Adolescent Urology. India: Jaypee Brothers Medical Publishers (P) Ltd; 2019. Chapter 87, Training in Percutaneous Nephrolithotomy; p. 861

12. Noureldin YA, Fahmy N, Anidjar M, Andonian S (2016) Is there a place for virtual reality simulators in assessment of competency in percutaneous renal access? World J Urol 34:733-739

13. Mishra S, Kurien A, Ganpule A, Muthu V, Sabnis R, Desai M (2010) Percutaneous renal access training: content validation comparison between a live porcine and a virtual reality (VR) simulation model. BJU Int 106(11):1753-1756. https://doi.org/10.1111/j.1464-410X.2010.09753.x

14. Karagozlu Akgul A, Unal D, Demirbas M, Oner S, Ucar M, Akgul K, Guzelsoy M, Aydos M (2018) A simple, non-biological model for percutaneous renal access training. Urol J 15(2):1-5. https://doi.org/10.22037/uj.v0i0. 3805 (PMID: 29250765)

15. Zang Y, Yu CF, Jin SH, Li NC, Na YQ (2014) Validation of a novel non biological bench model for the training of percutaneous renal access. Int Braz J Urol 40:87-92

16. Sinha M, Krishnamoorthy V (2015) Use of a vegetable model as a training tool for PCNL puncture. Indian J Urol 31(2):156-159. https://doi.org/10. 4103/0970-1591.152922

17. Veneziano D, Smith A, Reihsen T, Speich J, Sweet RM (2015) The SimPORTAL fluoro-less C-arm trainer: an innovative device for percutaneous kidney access. J Endourol 29:240-245

18. Abboudi $H$, Khan MS, Guru KA et al (2014) Learning curves for urological procedures: a systematic review. BJU Int 114(4):617-629. https://doi.org/ 10.1111/bju.12315

19. Kyriazis I, Liatsikos E, Sopilidis O, Kallidonis P, Skolarikos A (2017) European Section of Urotechnology (ESUT). European Section of Urotechnology educational video on fluoroscopic-guided puncture in percutaneous nephrolithotomy: all techniques step by step. BJU Int 120(5):739-741. https://doi.org/10.1111/bju.13894

20. PCNL radiation free perc simulator(n.d.) Available from: https://www.india mart.com/proddetail/pcnl-radiation-free-perc-simulator-21003498912. html

\section{Publisher's Note}

Springer Nature remains neutral with regard to jurisdictional claims in published maps and institutional affiliations. 